\title{
Decomposing supply-side and demand-side impacts of climate change on the US electricity system through 2050
}

\author{
Daniel C. Steinberg ${ }^{1}$ (D) Bryan K. Mignone ${ }^{2} \cdot$ Jordan Macknick $^{1} \cdot$ Yinong Sun $^{1}$ • \\ Kelly Eurek ${ }^{1} \cdot$ Andrew Badger $^{3} \cdot$ Ben Livneh $^{3,4} \cdot$ Kristen Averyt $^{5}$ \\ Received: 22 June 2018 / Accepted: 19 July 2019 / Published online: 3 January 2020 \\ (C) ExxonMobil Research and Engineering Company, The National Renewable Energy Laboratory 2020, corrected \\ publication 2020
}

\begin{abstract}
Climate change may affect the US electricity system through changes in electricity demand, mediated by increases in average surface temperature, and through changes in electricity supply, mediated by changes in both surface temperature and regional water availability. By coupling projections from four general circulation models (GCMs) with a state-of-the-art US electricity system model - the Regional Energy Deployment System (ReEDS) - this study evaluates both the isolated and combined effects of different climate-mediated drivers of US electricity system change through 2050. Comparing results across climate models allows us to evaluate which effects are robust to uncertainty in projected climate outcomes. Comparing effects of different drivers in isolation and in combination allows us to determine the relative contributions of the climate-mediated effects on system evolution. Our results indicate that national-level energy and economic impacts are largely driven by increases in electricity demand that follow from a consistent increase in surface air temperature that is largely robust to the choice of climate model. Other electricity system changes can be equally or more significant in some regions, but these effects are more regionally variable, less significant when aggregated to the national scale, and less robust to the choice of climate model. The findings show that the impacts of climate change on the electricity system can be understood in terms of fewer drivers and with greater certainty at the national level than at the regional level.
\end{abstract}

\section{Introduction}

Climate change may affect the evolution of the energy sector through several pathways that alter energy demand or energy supply. On the demand side, changes in air temperature can

The original version of this article was revised due to a retrospective open access order.

Electronic supplementary material The online version of this article (https://doi.org/10.1007/s10584-01902506-6) contains supplementary material, which is available to authorized users.

Daniel C. Steinberg

daniel.steinberg@nrel.gov

Extended author information available on the last page of the article 
alter energy consumption for space heating and cooling - generally increasing electricity consumption for cooling and decreasing consumption of electricity, natural gas, and oil for heating (Sailor and Muñoz 1997; Hor et al. 2005; Mansur et al. 2008). On the supply side, changes in temperature and water availability can alter electricity system dispatch (operation) and expansion (investment). Higher air temperatures can reduce the efficiency and the maximum capacity of thermal power plants (ICF 1995; Jaglom et al. 2014; González-Díaz et al. 2017; Miara et al. 2017), increase water usage rates at thermal plants (Rutberg et al. 2011), and reduce the effective capacity of electric transmission lines (Ward 2013; Sullivan et al. 2015). Changes in the seasonality, availability, and temperature of cooling water resources can constrain the operations and siting of thermal plants (DOE 2013; Macknick et al. 2016). ${ }^{1}$ In addition, changes in the seasonality and total quantity of water resources available can constrain the operations of hydro-electric plants (DOE 2016; Liu et al. 2017). While other impact pathways are possible, such as changes in wind patterns and cloud cover altering the quality of wind and solar generation resources (Craig et al. 2019), they are outside the scope of this study. A more comprehensive list of impact pathways and their relationship to this study is provided in the Supplementary Material.

Given the complex interaction between the climate and energy systems, this interaction has been an active area of research for over two decades (Rosenthal et al. 1995). However, the literature on climate-mediated energy system impacts has evolved unevenly, with the dominant strand of research focused on energy demand and a more limited strand focused on energy supply. Demand-side effects have been explored using a variety of approaches, including empirical and econometric methods (Sailor and Muñoz 1997; Sailor 2001; Sailor and Pavlova 2003; Franco and Sanstad 2008; Mansur et al. 2008; Miller et al. 2008; Asadoorian et al. 2008; Pilli-Sihvola et al. 2010; Deschênes and Greenstone 2011; Auffhammer and Aroonruengsawat 2011; Davis and Gertler 2015; Allen et al. 2016; Huang and Gurney 2016, 2017; Auffhammer et al. 2017; Wenz et al. 2017), and methods utilizing both energy system models (Hadley et al. 2006) and integrated assessment models (Isaac and van Vuuren 2009; Zhou et al. 2013, 2014; Clarke et al. 2018).

The literature focused on demand spans multiple scales, with some studies focused on global impacts (e.g., Isaac and van Vuuren 2009) and others focused on more detailed outcomes at the national level (e.g., Auffhammer et al. 2017) or state level (e.g., Franco and Sanstad 2008). In addition, some of the studies focus on changes in electricity demand, which are largely driven by changes in cooling demand (e.g., Wenz et al. 2017), while others focus on changes in both heating and cooling demands (e.g., Huang and Gurney 2016) and the associated changes in electricity and fossil fuel consumption. Finally, many empirical studies focus on intensive margin (or short-term) effects assuming that the underlying capital stock does not change (e.g., Mansur et al. 2008), while a smaller number explicitly include extensive margin effects (capital stock changes), such as greater air conditioner adoption (e.g., Sailor and Pavlova 2003; Davis and Gertler 2015).

In contrast to research on energy demand, the literature exploring the impacts of climate change on energy supply is less extensive and has primarily focused on the electricity sector. ${ }^{2}$ The more limited focus on the supply side is likely due to complexities in modeling these

\footnotetext{
${ }^{1}$ Among the different types of climate changes that have been projected, changes in air temperature and potential changes in water availability are the most likely to affect the US electricity sector over the next several decades, provided that the system continues to be dominated by thermal generation over this period (DOE 2013).

${ }^{2}$ See Arent et al. 2014 for a review of studies that have considered impacts on other energy supply sub-sectors.
} 
effects, given the larger number of potential impact pathways relative to the demand side, and, in the case of the power sector, the high degree of interconnection and interdependence across regions. For example, the electric grid responds flexibly to imposed changes, meaning that generation responses in one region will depend on imposed changes in many other regions due to the ability to exchange energy, capacity, and other grid services between regions. Indeed, studies that have focused on energy supply to date have not captured all relevant responses simultaneously, but have focused on a single or a limited set of components isolated from others, such as air temperature impacts on thermal efficiencies or water availability on generation potential (ICF 1995; Rutberg et al. 2011; van Vliet et al. 2012, 2016; Jaglom et al. 2014; Macknick et al. 2015, 2016; González-Díaz et al. 2017).

Recently, some studies have begun to examine the combined impacts of supply- and demand-side changes using dynamic modeling tools, focusing on the US electricity system (Jaglom et al. 2014; McFarland et al. 2015) and the European electricity system (Dowling 2013). These approaches have potential to fill in the gaps left by other studies, but to date, they have only considered a subset of supply-side changes, namely effects that result from changes in ambient air temperatures.

The study described here builds on the prior literature in several ways. First, it considers combined effects of climate change impacts on US electricity supply and demand. Second, it decomposes simulated impacts into (i) those resulting from changes in air temperature and those resulting from changes in water availability and (ii) those being driven by changes in demand and those being driven by changes in supply. This decomposition allows us to determine which drivers have the greatest impact on particular outcome variables. Third, it examines impacts at both the national and state levels to determine whether key drivers depend on the spatial scale of interest. Finally, it considers the decomposition separately for four sets of scenarios driven by four separate climate models from the Coupled Model Intercomparison Project Phase 5 (CMIP5) archive (Taylor et al. 2011). This allows us to determine which outcomes are robust to the choice of climate model and thus to the associated differences in changes in projected future temperatures and water availabilities.

Section 2 describes the modeling and decomposition approach in more detail. Section 3 describes key findings at the national and state level. Section 4 discusses these results and provides explanations in terms of basic assumptions and system characteristics where possible. Section 5 concludes with a summary of broader implications and possible directions for future research.

\section{Methods}

We use the National Renewable Energy Laboratory's Regional Energy Deployment System (ReEDS) model to explore the isolated and combined effects of climate-induced changes in air temperature and water availability on US national and regional power sector evolution. We explore both changes in the consumption of electricity, driven by changes in ambient air temperatures and the associated space conditioning loads, and changes in the supply of electricity, driven by changes in ambient air temperature and water availability, and the associated impacts on the operation and expansion of the generation and transmission system. Given the variability and uncertainty in future temperature and water availability trajectories, we explore these effects using temperature and precipitation projections from a diverse set of four climate models that participated in CMIP5, each following the Representative 
Concentration Pathway (RCP) 4.5 scenario (Thomson et al. 2011). The four climate models were selected to capture the range of temperature and runoff conditions observed across the full ensemble of CMIP5 RCP4.5 projections (cooler/drier, cooler/wetter, warmer/drier, and warmer/wetter) ${ }^{3,4,5}$ With these climate inputs, a total of 29 scenarios (4 climate projections, 7 climate-mediated effects, and 1 counterfactual no climate change scenario) have been produced using ReEDS to quantify the potential supply- and demand-side impacts of climate change on the US power sector through 2050.

\subsection{ReEDS model}

ReEDS is a linear programming model that solves for the least-cost investment (expansion) and operation of the generation and transmission system in the contiguous USA from present to 2050 (Eurek et al. 2016). Relative to other national-scale power sector capacity expansion models, the model exhibits a high degree of spatial resolution (Mai et al. 2018;NREL 2017a). Generating units, transmission lines, and electricity load are characterized for 134 balancing areas (BAs), and renewable resources are characterized for 356 resource regions. Dispatch of generating units is optimized over 17 chronological "time slices" that represent an approximation of hourly electricity load shapes throughout the year - a morning, afternoon, evening, and night period of a representative day in each of the four seasons - as well as the 17th "super-peak" time slice representing the top 40 consecutive load hours of the year. In addition, the model uses a suite of statistical methods to address issues associated with variable renewable energy integration.

Two features of ReEDS are particularly significant for this analysis. First, ReEDS captures water withdrawal and consumption requirements of thermal power plants and the associated constraints on plant dispatch and siting (Macknick et al. 2015). Second, the model is well suited to capture changes in the electricity system that result from regional changes in temperature and water availability due to its high degree of spatial detail.

\subsection{Representation of climate impacts in ReEDS}

The ReEDS model captures impacts of climate change on demand, mediated by increased temperatures that in turn affect electricity demands for space conditioning, and on supply, mediated by both changes in surface air temperature and water availability. On the demand side, the effect of increases in surface temperature on space heating and cooling loads (relative to a counterfactual no climate change case) is captured through empirically derived relationships between changes in load and changes in heating degree days (HDDs) and cooling degree days (CDDs) (Sullivan et al. 2015). These relationships are determined separately for each

\footnotetext{
${ }^{3}$ To keep the number of cases manageable, we chose to focus on a single RCP. RCP4.5 is a natural choice given that it is neither the scenario with the highest nor the scenario with the lowest forced warming. Mean reported temperature changes for the period from 2046 to 2065 (relative to $1986-2005$ ) range from $1.0{ }^{\circ} \mathrm{C}$ (RCP2.6) to $2.0{ }^{\circ} \mathrm{C}$ (RCP8.5), with temperatures in RCP4.5 and RCP6.0 reaching 1.4 and $1.3{ }^{\circ} \mathrm{C}$, respectively (IPCC 2014).

${ }^{4}$ A detailed discussion of the methods used to select climate models is included in the Supplementary Material. ${ }^{5}$ We acknowledge the World Climate Research Programme's Working Group on Coupled Modelling, which is responsible for CMIP, and we thank the climate modeling groups (listed in Figure SM 1) for producing and making available their model output. For CMIP, the US Department of Energy's Program for Climate Model Diagnosis and Intercomparison provides coordinating support and led development of software infrastructure in partnership with the Global Organization for Earth System Science Portals.
} 
region (BA) and time slice (season and time of day) to capture spatial and temporal variation in space conditioning loads and their sensitivity to ambient temperature. ${ }^{6}$

On the supply side, several effects are considered. Climate-induced changes in the availability of cooling water affect the operation of existing and future power plants (we will refer to this category of impact as "Water-on-Gen"). Changes in surface temperature affect the operating efficiency (heat rate), water usage rates for cooling, and the maximum capacity of thermal power plants (we will refer to this category of impact as "Temp-on-Gen"). Finally, changes in surface temperature affect the effective capacity (due to thermal limits) of transmission lines (we will refer to this category of impact as "Temp-on-Trans"). The demand-side impacts will be referred to as "Temp-on-Demand."

The effects of changes on water availability are captured through a framework that jointly represents the availability and cost of water to the power sector, and the cooling water demands of individual power plants. Each BA within the model is allocated a seasonally specific level of water access availability and cost for up to five resource categories: unappropriated freshwater, appropriated freshwater, fresh groundwater, brackish groundwater, and wastewater, based on estimates defined by state water managers (Liang et al. 1994; Tidwell et al. 2013; Tidwell et al. 2014; Macknick et al. 2015). Existing plants are assigned cooling efficiencies and associated withdrawal rates (designated in gallons per $\mathrm{MWh}$ ) based on the type of generator and cooling technology used. Cooling technologies for new units and upgrades to existing units are optimally selected based on their capital cost and efficiency and on the cost and availability of water resources.

To represent water constraints on the dispatch of thermal plants in any given year, sufficient water must be available to meet the withdrawal requirements ${ }^{7}$ of all operating power plants. Similarly, to represent constraints on investment in new thermal capacity, sufficient water must be available to meet withdrawal requirements of the plant operating at full capacity for a year. Under climate change scenarios, the reference water resource supply curves are modified based on projected changes in surface water availability by year and season as discussed in the Supplementary Material.

The suite of temperature-mediated impacts on supply is captured within the model using engineering-based relationships available in the literature. The relationships between increased ambient air temperatures and decreased power plant efficiencies and maximum capacities are based on Jaglom et al. (2014); the relationships between temperature and water usage rates are based on Rutberg et al. (2011); the relationship between increased temperature and decreased effective transmission line capacity is based on ICF (1995).

Some temperature- and water-mediated effects (stream temperature effects, effects on hydropower) are not considered in our analysis and are not expected to substantially alter outcomes of this research. Section S3 in the Supplementary Material includes a table that summarizes potential pathways of climate impacts on the power system that have been identified in the literature.

\footnotetext{
${ }^{6}$ Since the relationship between load changes and temperature changes are empirically derived, these relationships capture the covariance of temperature and specific humidity in the real world and thus implicitly capture the relationship between load changes and specific humidity. The calibration also captures regional differences in relative humidity. For example, the slope of the relationship between load and temperature for a region with low relative humidity may be different than for a region with high relative humidity. Changes in relative humidity are projected to be small relative to internal variability over the projection period (Kirtman et al. 2013).

${ }^{7}$ Plant-level water consumption rates are always less than or equal to withdrawal rates, and thus, consumption is implicitly constrained through the set of withdrawal constraints.
} 
Table 1

\begin{tabular}{|c|c|c|c|c|c|c|}
\hline \multirow{2}{*}{$\begin{array}{l}\text { Scenario } \\
\text { Category }\end{array}$} & \multirow[t]{2}{*}{ Scenario Name } & \multirow{2}{*}{$\begin{array}{l}\text { Scenario Short } \\
\text { Name }\end{array}$} & \multicolumn{4}{|c|}{ Climate Impact Considered in ReEDS } \\
\hline & & & $\begin{array}{l}\text { Temp on } \\
\text { Demand }\end{array}$ & $\begin{array}{l}\text { Temp on } \\
\text { Generation }\end{array}$ & $\begin{array}{l}\text { Temp on } \\
\text { Transmission }\end{array}$ & $\begin{array}{l}\text { Water on } \\
\text { Generation }\end{array}$ \\
\hline No Climate & No Climate Change & No-ClimChg & - & - & - & - \\
\hline \multirow[t]{4}{*}{ In Isolation } & Temp-on-Demand & Temp-Dem & Included & - & - & - \\
\hline & Temp-on-Generation & Temp-Gen & - & Included & - & - \\
\hline & Temp-on-Transmission & Temp-Trans & - & - & Included & - \\
\hline & Water-on-Generation & Water-Gen & - & - & - & Included \\
\hline \multirow[t]{3}{*}{ In Combination } & All Temp Effects & All-Temp & Included & Included & Included & - \\
\hline & All Supply Effects & All-Supply & - & Included & Included & Included \\
\hline & All Effects & All & Included & Included & Included & Included \\
\hline
\end{tabular}

\subsection{Scenario design}

For each of the four climate projections (each following the RCP 4.5 scenario (Thomson et al. 2011)), we explore the power sector implications of four categories of climate effects (Tem$\mathrm{p}$ [erature]-on-Demand, Temp-on-Gen[eration], Temp-on-Trans[mission], and Water-on-Gen[eration]) in isolation and in combination (Table 1). ${ }^{8}$ The three combined scenarios examine the electric sector responses to all air temperature-induced impacts (on demand, generation, and transmission), all supply-side impacts, and the full suite of climate impacts described above, resulting in a total of 7 climate change impact scenarios for each climate model projection. ${ }^{9}$ In addition, a counterfactual (or control) scenario with no climate change is run for comparison. All other assumptions are constant across scenarios. Generator cost and performance inputs are taken from the 2017 Annual Technology Baseline (NREL 2017b), and reference electricity demand and fuel prices are based on the Energy Information Administration's Annual Energy Outlook (AEO) 2017 Reference Case (EIA 2017). State and federal policies are represented as of June 1, 2017, including state renewable portfolio standards, California's Assembly Bill 32 rule, the Regional Greenhouse Gas Initiative (RGGI), and federal tax incentives (Eurek et al. 2016).

\section{Results}

\subsection{National results}

Under the No-ClimChg case, decreasing generation from coal and nuclear sources-largely due to plant retirements - is replaced with increased generation from natural gas combined cycle (NG-CC), wind, and solar photovoltaic (PV) technologies (Fig. 1). The capacity mix follows a similar trajectory, but also shows significant growth in natural gas combustion

\footnotetext{
${ }^{8}$ See the Supplementary Material for a discussion of climate model selection and how climate model outputs are translated into inputs to ReEDS.

${ }^{9}$ In the main body of this paper, we only report results for the isolated scenarios and the "All" combined scenario - which includes all supply- and demand-side climate impact pathways. Results from the "All-Temp" and "All-Supply" combined scenarios are reported in the Supplementary Material.
} 

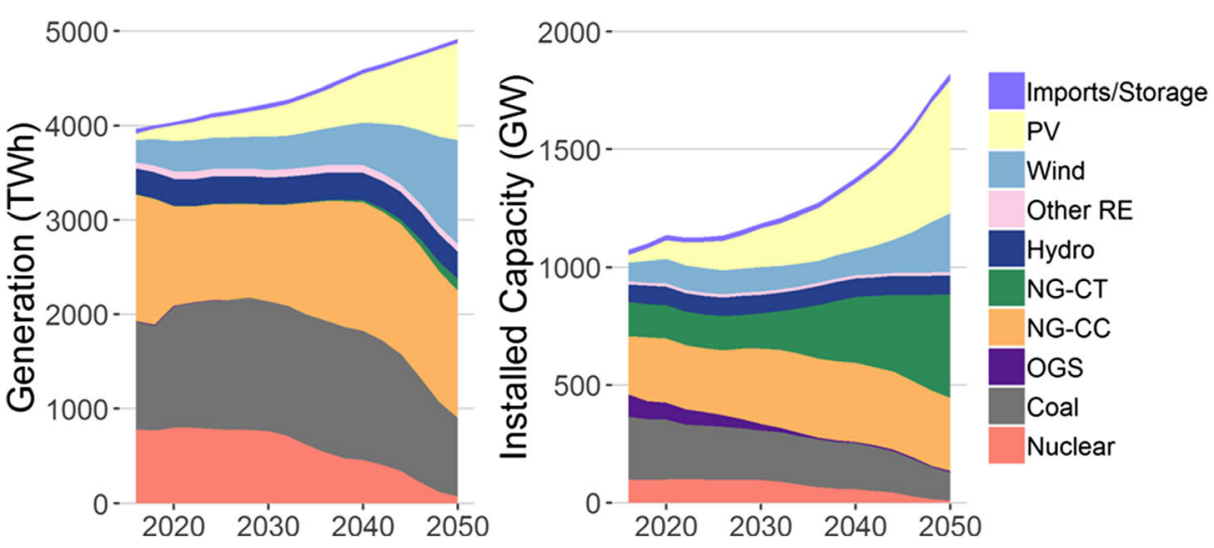

Fig. 1 Generation (left) and capacity (right) by technology under the No-ClimChg scenario from 2015 to 2050. OGS refers to simple cycle oil or gas (or dual fuel) steam plants. Generation imports (from Canada and Mexico) only apply to the Generation chart; storage capacity only applies to Installed Capacity chart

turbine (NG-CT) capacity. Although NG-CT capacity does not provide a substantial amount of generation, it is built to meet planning reserve requirements (which increase with increasing peak load), to offset retired coal and nuclear capacity, and to provide additional flexibility to aid in the integration of variable wind and solar generation (Fig. 1).

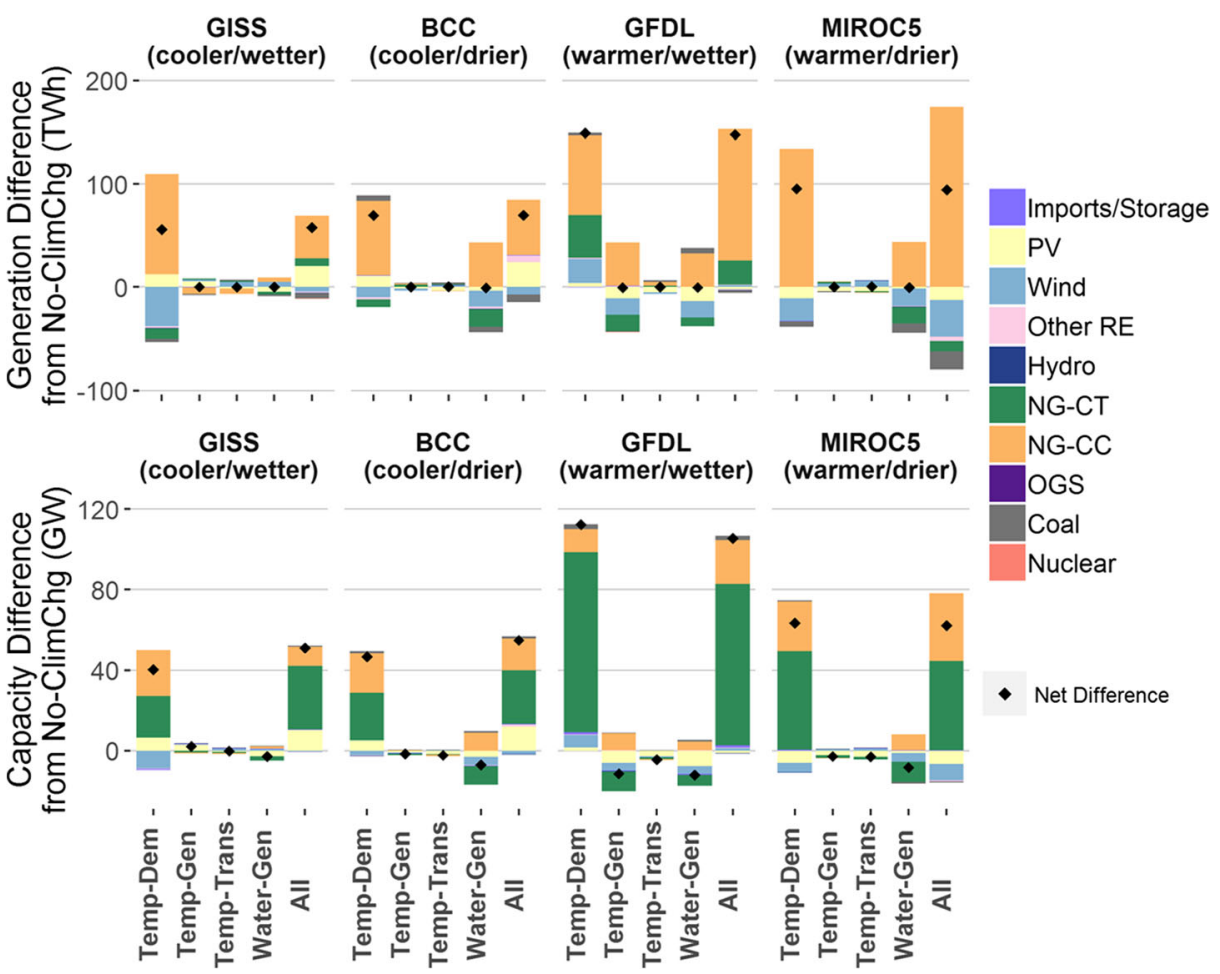

Fig. 2 Change in generation (top row) and capacity (bottom row) in 2050 relative to the No-ClimChg scenario across all climate projections and selected impact scenarios 
Table 2 Changes in total discounted electricity system cost from the No-ClimChy scenario between 2015 and 2050 (5\% discount rate, billion 2016\$). Total discounted system cost for the NoClimChg scenario between 2015 and 2050 is 2,650 billion $2016 \$$

\begin{tabular}{lllll}
\hline \multicolumn{5}{c}{ Climate model } \\
\cline { 2 - 5 } Climate impacts & $\begin{array}{l}\text { GISS } \\
\text { (cooler/ } \\
\text { wetter) }\end{array}$ & $\begin{array}{l}\text { BCC } \\
\text { (cooler/ } \\
\text { drier) }\end{array}$ & $\begin{array}{l}\text { GFDL } \\
\text { (warmer/ } \\
\text { wetter) }\end{array}$ & $\begin{array}{l}\text { MIROC5 } \\
\text { (warmer/ } \\
\text { drier) }\end{array}$ \\
\hline Temp-on-Demand & 36 & 48 & 110 & 71 \\
Temp-on-Gen & $<1$ & 2 & 1 & $<1$ \\
Temp-on-Trans & $<1$ & $<1$ & $<1$ & $<1$ \\
Water-on-Gen & $<1$ & 2 & 3 & 3 \\
All & 37 & 54 & 118 & 75 \\
\hline
\end{tabular}

Net increases in capacity and generation under the $A l l$ scenario are about $2-3 \%$, and these increases are largely driven by increasing demand due to increasing temperatures (Fig. 2). Net changes due to temperature- and water-mediated impacts on energy supply are negligible both individually (Fig. 2) and in aggregate (see the All-Supply column of Figs. SM 9 and SM 10). Despite this, apart from the Temp-Trans effect, all effects induce some change in the mix of generation or capacity under at least one of the climate projections. For example, changes in water availability lead to changes in the generation mix in three of the four climate projections, with NG-CC technologies displacing generation from PV, wind, and NG-CT technologies.

Table 2 shows changes in total system costs relative to the No-ClimChg scenario associated with each of the isolated climate impacts scenarios as well as from the fully integrated All scenario. The total electricity system cost - the present value of all fixed and variable (including fuel) costs of meeting load from present day to 2050 - increases by $1-4 \%$ in the All scenario compared with the No-ClimChg scenario, depending on the climate projection considered. The majority of those costs are associated with increased demand for electricity. Climate-induced effects on generation (e.g., reduced generator efficiency, changes in water availability) drive smaller increases in total system cost.

\subsection{Regional results}

Changes in total state-level generation show considerable variability across states. In addition, the relative changes in generation due to changes in temperature or water availability are considerably higher in some states than the relative change in national generation (Fig. 3). Focusing on the Temp-Demand impacts (left), the response of state-level generation to increased temperature can be positive, negative, or negligible, despite consistent temperature increases across states. It is also worth noting that the response of generation in many states is consistent across climate modelseither uniformly positive or uniformly negative. The plot showing the Water-Gen scenario (center) demonstrates that there are no consistent changes in water availability across models-for practically all states, at least one model projects an increase in water availability and at least one model projects a decrease in water availability. ${ }^{10}$ Despite the differences in projected changes in water availability across models, the changes in state-level generation resemble the changes in

\footnotetext{
${ }^{10}$ The observation that water availability may increase or decrease, depending on the scenario, is consistent with what is known about changes in precipitation under climate change. For example, a comparison of climate model results by the IPCC shows that projected precipitation changes are small compared with internal variability over the next several decades (Kirtman et al. 2013). Small changes around the mean state, as observed here, are thus consistent with this finding.
} 

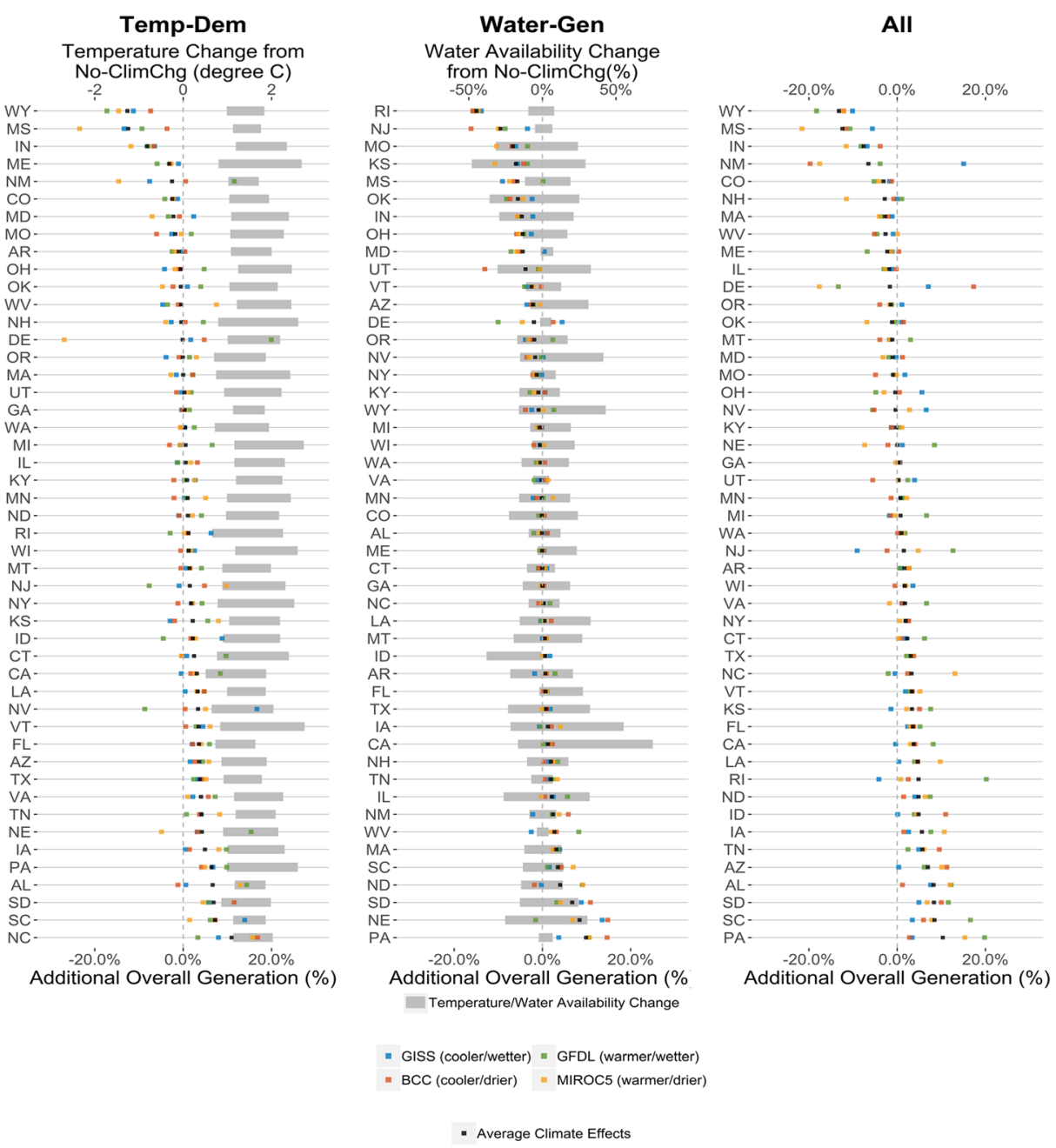

Additional Overall Generation (\%)

Fig. 3 Change in total state generation from the No-ClimChg scenario under the Temp-Demand scenario (left), the Water-Gen scenario (center), and the All scenario (right) across the four climate projections (colored dots), ordered from top to bottom by the size of the average change in generation across the four climate projections (black dot) for the impact scenario considered; dots correspond to the bottom $x$-axis. Also shown are the range of temperature (left) and water availability changes (center) in 2050 across the suite of climate projections (gray bars); gray bars correspond to the top $x$-axis

response to the Temp-Demand scenario, in the sense that the responses can be positive, negative, or negligible, and there is often a consistent change within a given state.

\section{Discussion}

The variations in generation and capacity in response to the individual and combined climate impacts suggest that the response of the electricity system to climate change depends on the 
scale of interest. At the national level, the dominant effect is the increase in generation and capacity driven by increases in electricity demand resulting from higher air temperatures. This effect is robust to the choice of climate model, although the magnitude depends on the magnitude of the temperature response, which depends on the climate model. The impacts of other temperature and water availability-mediated effects on net generation and capacity changes are considerably smaller than the Temp-Demand effect across all climate models.

Since increases in air temperature are ubiquitous, it is intuitive that the Temp-Demand effect would have a significant impact on the electricity system. However, there are two aspects of the national-level results that are less intuitive. One is the amount by which the Temp-Demand effect dominates all other air temperature and water availability effects at the national level. Another is that most of the increase in generation and capacity in the Temp-Demand case is provided by natural gas, even though both wind and solar technologies are assumed to achieve substantial cost reductions over the study period and future natural gas prices are assumed to be higher than current prices.

The dominance of the Temp-Demand effect can be explained by examining the representation of the different effects in ReEDS. Empirical estimates of the sensitivity of load to increases in temperature (Sullivan et al. 2015) that are used in ReEDS generally indicate a 1$2 \%$ increase in load per ${ }^{\circ} \mathrm{C}$ increase in air temperature (due to increases in space cooling demand), with a significant amount of regional variability. At the same time, estimates suggest a somewhat smaller sensitivity of load to decreases in temperatures (due to lower heating demand during colder months). Since the average increase in air temperature in 2050 is about $1-2{ }^{\circ} \mathrm{C}$ across the models, we might expect a $1-4 \%$ increase in generation $(50-200 \mathrm{TWh}$, assuming $\sim 5000 \mathrm{TWh}$ in 2050), which is consistent with results shown in Fig. 2.

This Temp-Demand effect on generation can be contrasted with the other temperature- and water availability-mediated effects on generation. None of the other effects change the overall amount of electricity demanded, so at a national level, we would expect the net change in generation from these other effects to be small, which is also consistent with Fig. 2. That said, decreases in the maximum capacity of power plants or transmission lines may increase the need for additional generation capacity even if overall electricity demand - and the need for generation - is unchanged.

However, the impacts on capacity from other effects are likely to be considerably smaller than the impacts from the Temp-Demand effect for three reasons. First, the sensitivity of maximum power plant and transmission line capacity to temperature is less than $1 \%$ per ${ }^{\circ} \mathrm{C}$, which is smaller than the sensitivity associated with the Temp-Demand effect. Second, in the case of Temp-Gen and Temp-Trans, these effects are not likely to be material in some regions because not all regions face binding transmission constraints or binding reserve margin constraints. That is, they have excess generation or transmission capacity, in which case reductions in capacity may not alter the outcome. Third, in the case of Water-Gen effects, water availability may increase in some regions, alleviating rather than exacerbating pressure from this constraint, and, as with the other effects, water constraints are not binding in some regions.

The disproportionate share of natural gas deployed in response to the Temp-Demand effect can be understood by examining the change in the load shape that occurs in addition to the increase in overall load that results from increased air temperatures. Since increases in demand are largely due to space cooling, this impact is concentrated in peak demand time periodsprimarily afternoon hours on hot days (Fig. SM 8). Natural gas technologies are deployed to satisfy the additional need for flexible generation, as well as the need for capacity to satisfy 
reserve margins as the required amount of peak capacity increases. The additional capacity that deploys in this case is a mix of NG-CCs, which satisfy the need for additional generation (Fig. 2, top row), and NG-CTs, which satisfy the need for additional reserve capacity (Fig. 2, bottom row).

From these additional considerations, it is clear why the Temp-Demand effects on both generation and capacity are more significant than the Temp-Gen, Temp-Trans, and Water-Gen effects. In the case of generation, only the Temp-Demand effect increases the overall demand for electricity and therefore the need for additional net generation on a national scale. In the case of capacity, only the Temp-Demand effect increases the peak-to-average ratio and therefore the need for additional net capacity to satisfy reserve margins. The other effects alter the need for capacity in some regions, but do not consistently do so across all regions, leading to smaller changes in net capacity at a national level. ${ }^{11}$

At the regional level, there is a lack of correlation between the electricity system response in a given region and the physical climate response in that region. This effect is most apparent in the left panel of Fig. 3, in which the regional temperature responses are all observed to be positive while the changes in generation (due to the Temp-Demand effect) are both positive and negative by 2050 . The national-level results, and the explanation for those results, guarantee that the sum of the regional changes in generation is positive, but the same reasoning does not constrain the regional results in a model in which electricity can be exchanged between regions and in which regional demands for electricity can be satisfied more cost-effectively by increasing generation in one region and decreasing it another. An implication of this result is that, while the changes in the electricity system at the national level can be directly related to changes in climate, changes in the electricity system at the regional level are more likely to be determined by the relative costs of providing electricity within a particular region than by the changes in climate in that region.

Regional results in the Water-Gen scenario (Fig. 3, center panel) largely confirm the TempDemand explanation; comparable changes in water availability across different regions may lead to increases in generation in one region, but decreases in generation in another. A key difference, however, is that the projected changes in water availability can be substantially different across models. This result suggests that given uncertainty in regional water availability projections across climate models, regardless of the fidelity of the electricity system representation, water-mediated climate impacts on electricity are not likely to be projected with confidence at the regional level, making scenario and uncertainty analysis of water availability essential to fully understand the range of possible outcomes. That said, the electricity system responses exhibit a general pattern that is similar to the Temp-Demand effect, with some regions having consistently lower generation and some having consistently higher generation when perturbed by a change in climate. This result supports the explanation above that the primary driver of results in a given region is the regional variation in cost and other features of the electricity system, rather than changes in climate in that region. This also explains how some states with relatively large changes in water availability exhibit minimal changes in generation, and states with relatively small changes in water availability exhibit relatively large changes in generation.

Finally, although the Temp-Demand effect tends to drive first-order changes in generation and capacity, interaction effects with other supply-side drivers can alter the mix of technologies in some cases. For example, in the warmer and drier climate scenario, the All scenario exhibits

\footnotetext{
${ }^{11}$ In Fig. 2, net capacity decreases under several impact scenarios and climate projections. Whenever NG-CC displaces wind or solar PV generation and net generation is unchanged, total capacity will decrease due to the differences in average capacity factors between these technologies.
} 
net generation differences comparable to the Temp-Demand scenario, but there is more fuel switching in the All scenario. NG-CC generation differences are $30 \%$ higher in the All scenario, presumably a result of the fact that lower water availability constrains coal generation. Conversely, in the cooler and wetter climate scenario, there is less fuel switching in the All scenario than in the Temp-Demand scenario, even though changes in net generation are roughly equivalent.

\section{Conclusions}

This paper extends prior work exploring climate change impacts on the electricity system in several important ways. First, it considers the combined effects of climate change impacts on US electricity supply and demand using scenarios that are complementary to those explored elsewhere. Second, it decomposes simulated impacts into those resulting from changes in temperature and those resulting from changes in water availability, and into those being driven by changes in demand and those being driven by changes in supply. Finally, the analysis was performed using the output from four separate climate models with different temperature and water projections from the CMIP5 archive in order to determine which outcomes are robust to the choice of climate model.

Results from this study suggest that the national-level impacts in generation, capacity, and cost are largely driven by increases in electricity demand that follow from a consistent increase in surface air temperature that is largely robust to the choice of climate model. This result can be explained by the fact that only the Temp-Demand effect increases total electricity demand (thus demand for additional net generation) and the peak-to-average ratio (thus demand for additional net capacity to meet reserve margins). Other effects are less nationally significant because transmission, reserve margin, and water constraints do not bind everywhere, and in the case of water, water availability may increase rather than decrease in some regions.

Results further suggest that the set of regional responses can be understood in terms of the system flexibility that electricity transmission provides. Since electricity can be traded across regions, regional results are determined to a large extent by the relative costs of producing and transmitting electricity, rather than by the regional climate changes alone. The regional responses are even more difficult to project for water-mediated changes because regional water availability responses are not robust to the choice of climate model.

More broadly, this work suggests that the emphasis on demand effects when evaluating climate change impacts is appropriate for studies whose goal is to estimate aggregate impacts at the national level or above. In this realm, coarser models, including integrated assessment models, may be sufficient for estimating aggregate impacts (Clarke et al. 2018). On the other hand, if the goal of such research is to inform adaptation planning at the sub-national level, then granularity is essential. This study suggests that, regardless of the model, uncertainties will be magnified at the regional scale because electricity system effects at these scales may depend on climate change effects outside the region of interest (which are sensitive to how the electricity system is represented) and because the climate information (particularly information about water) may not be robust at these scales.

Finally, this study suggests several possible directions for future research. First, the sensitivity to other climate projections (RCPs) and projections beyond 2050 might be considered. Although not all effects that might be observed under different climate projections or in later years can be anticipated from the results of this study, it is likely that the magnitude of the 
Temp-Demand effect will scale with surface air temperature and therefore that this effect would be larger under RCP 8.5 than under RCP 4.5 (in a given year) and that it would be larger in 2100 than in 2050 (for a given climate projection). Second, our study does not consider the effects of shorter term climate variability, including potential changes in such variability, the effects of potential impact pathways other than those described explicitly (see Table SM1), or the effects of interactions between economic sectors, such as how changes in water availability may differentially affect the energy and agricultural sectors. Each of these topics could be considered using extensions to the current approach or by considering alternative models and methods where appropriate.

Funding information The authors from NREL and the University of Colorado Boulder received support from the ExxonMobil Research and Engineering Company.

Disclaimer This work was authored in part by the National Renewable Energy Laboratory, operated by Alliance for Sustainable Energy, LLC, for the U.S. Department of Energy (DOE) under Contract No. DEAC36-08GO28308. The views and opinions expressed in this article are those of the authors alone, and do not necessarily represent the views of the DOE or the U.S. Government.

Open Access This article is licensed under a Creative Commons Attribution 4.0 International License, which permits use, sharing, adaptation, distribution and reproduction in any medium or format, as long as you give appropriate credit to the original author(s) and the source, provide a link to the Creative Commons licence, and indicate if changes were made. The images or other third party material in this article are included in the article's Creative Commons licence, unless indicated otherwise in a credit line to the material. If material is not included in the article's Creative Commons licence and your intended use is not permitted by statutory regulation or exceeds the permitted use, you will need to obtain permission directly from the copyright holder. To view a copy of this licence, visit http://creativecommons.org/licenses/by/4.0/.

\section{References}

Allen MR, Fernandez SJ, Fu JS, Olama MM (2016) Impacts of climate change on sub-regional electricity demand and distribution in the southern United States. Nat Energy 1:16103. https://doi.org/10.1038 /nenergy.2016.103

Arent D, Tol R, Faust E et al (2014) Key economic sectors and services. In: Climate change 2014: impacts, adaptation, and vulnerability. Part A: global and sectoral aspects. Contribution of working group II to the fifth assessment report of the intergovernmental panel on climate change, Cambridge, United Kingdom and New York, NY, USA

Asadoorian MO, Eckaus RS, Schlosser CA (2008) Modeling climate feedbacks to electricity demand: the case of China. Energy Econ 30:1577-1602. https://doi.org/10.1016/j.eneco.2007.02.003

Auffhammer M, Aroonruengsawat A (2011) Simulating the impacts of climate change, prices and population on California's residential electricity consumption. Clim Chang 109:191-210. https://doi.org/10.1007/s10584011-0299-y

Auffhammer M, Baylis P, Hausman CH (2017) Climate change is projected to have severe impacts on the frequency and intensity of peak electricity demand across the United States. Proc Natl Acad Sci 114:18861891. https://doi.org/10.1073/pnas.1613193114

Clarke L, Eom J, Marten EH et al (2018) Effects of long-term climate change on global building energy expenditures. Energy Econ In press

Craig MT, Losada Carreño I, Rossol M et al (2019) Effects on power system operations of potential changes in wind and solar generation potential under climate change. Environ Res Lett 14:034014. https://doi. org/10.1088/1748-9326/aaf93b

Davis LW, Gertler PJ (2015) Contribution of air conditioning adoption to future energy use under global warming. Proc Natl Acad Sci 112:5962-5967

Deschênes O, Greenstone M (2011) Climate change, mortality, and adaptation: evidence from annual fluctuations in weather in the US. Am Econ J Appl Econ 3:152-185. https://doi.org/10.1257/app.3.4.152

DOE (2013) US energy sector vulnerabilities to climate change and extreme weather. United States Department of Energy 
DOE (2016) Hydropower vision: a new chapter for America's 1st renewable electricity source. United States Department of Energy

Dowling P (2013) The impact of climate change on the European energy system. Energy Policy 60:406-417. https://doi.org/10.1016/j.enpol.2013.05.093

EIA (2017) Annual energy outlook 2017. Energy Information Administration

Eurek K, Cole W, Bielen D, et al. (2016) Regional energy deployment system (reeds) model documentation: version 2016. National Renewable Energy Lab.(NREL), Golden, CO (United States)

Franco G, Sanstad AH (2008) Climate change and electricity demand in California. Clim Chang 87:139-151. https://doi.org/10.1007/s10584-007-9364-y

González-Díaz A, Alcaráz-Calderón AM, González-Díaz MO et al (2017) Effect of the ambient conditions on gas turbine combined cycle power plants with post-combustion $\mathrm{CO}_{2}$ capture. Energy 134:221-233. https://doi.org/10.1016/j.energy.2017.05.020

Hadley SW, Erickson DJ, Hernandez JL et al (2006) Responses of energy use to climate change: a climate modeling study. Geophys Res Lett 33:L17703. https://doi.org/10.1029/2006GL026652

Hor C-L, Watson SJ, Majithia S (2005) Analyzing the impact of weather variables on monthly electricity demand. IEEE Trans Power Syst 20:2078-2085. https://doi.org/10.1109/TPWRS.2005.857397

Huang J, Gurney KR (2016) The variation of climate change impact on building energy consumption to building type and spatiotemporal scale. Energy 111:137-153. https://doi.org/10.1016/j.energy.2016.05.118

Huang J, Gurney KR (2017) Impact of climate change on U.S. building energy demand: financial implications for consumers and energy suppliers. Energy Build 139:747-754. https://doi.org/10.1016/j. enbuild.2017.01.077

ICF (1995) Potential effects of climate change on electric utilities. ICF International

IPCC (2014) Climate change 2014: synthesis report. Contribution of working groups I, II and III to the fifth assessment report of the intergovernmental panel on climate change. IPCC [Core Writing Team, R.K. Pachauri and L.A. Meyer (eds.)], Geneva, Switzerland

Isaac M, van Vuuren DP (2009) Modeling global residential sector energy demand for heating and air conditioning in the context of climate change. Energy Policy 37:507-521. https://doi.org/10.1016/j. enpol.2008.09.051

Jaglom WS, McFarland JR, Colley MF et al (2014) Assessment of projected temperature impacts from climate change on the U.S. electric power sector using the Integrated Planning Model@. Energy Policy 73:524-539. https://doi.org/10.1016/j.enpol.2014.04.032

Kirtman B, Power SB, Adedoyin AJ et al (2013) Near-term climate change: projections and predictability. In: Climate change 2013: the physical science basis. Contribution of Working Group I to the Fifth Assessment Report of the Intergovernmental Panel on Climate Change. Cambridge University Press, Cambridge, United Kingdom and New York, NY, USA

Liang X (1994) Two-layer variable infiltration capacity land surface representation for general circulation models. U.S. Environmental Protection Agency, U.S. Department of Energy, and National Aeronautics and Space Administration, University of Washington, Dept. of Civil Engineering, Seattle, WA

Liu L, Hejazi M, Li H et al (2017) Vulnerability of US thermoelectric power generation to climate change when incorporating state-level environmental regulations. Nat Energy 2:17109. https://doi.org/10.1038 /nenergy.2017.109

Macknick J, Cohen S, Newmark R et al (2015) Water constraints in an electric sector capacity expansion model. National Renewable Energy Laboratory (NREL), Golden, CO (United States)

Macknick J, Zhou E, O'Connel M et al (2016) Water and climate impacts on power system operations: the importance of cooling systems and demand response measures. NREL (National Renewable Energy Laboratory (NREL), Golden, CO (United States))

Mai T, Bistline J, Sun Y, Cole W, Marcy C, Namovicz C, Young D (2018) The role of input assumptions and model structures in projections of variable renewable energy: A multi-model perspective of the U.S. electricity system. Energy Economics 76:313-324. https://doi.org/10.1016/j.eneco.2018.10.019

Mansur ET, Mendelsohn R, Morrison W (2008) Climate change adaptation: a study of fuel choice and consumption in the US energy sector. J Environ Econ Manag 55:175-193. https://doi.org/10.1016/j.jeem.2007.10.001

McFarland J, Zhou Y, Clarke L et al (2015) Impacts of rising air temperatures and emissions mitigation on electricity demand and supply in the United States: a multi-model comparison. Clim Chang 131:111-125. https://doi.org/10.1007/s10584-015-1380-8

Miara A, Macknick JE, Vörösmarty CJ et al (2017) Climate and water resource change impacts and adaptation potential for US power supply. Nat Clim Chang 7:793-798. https://doi.org/10.1038/nclimate3417

Miller NL, Hayhoe K, Jin J, Auffhammer M (2008) Climate, extreme heat, and electricity demand in California. J Appl Meteorol Climatol 47:1834-1844. https://oi.org/10.1175/2007JAMC1480.1

NREL (2017a) Variable renewable energy in long-term planning models: a multi-model perspective. Golden, CO., National Renewable Energy Laboratory 
NREL (2017b) 2017 Annual technology baseline. https:/atb.nrel.gov/electricity/2017/summary.html. Accessed 17 Feb 2018

Pilli-Sihvola K, Aatola P, Ollikainen M, Tuomenvirta H (2010) Climate change and electricity consumptionwitnessing increasing or decreasing use and costs? Energy Policy 38:2409-2419. https://doi.org/10.1016/j. enpol.2009.12.033

Rosenthal DH, Gruenspecht HK, Moran EA (1995) Effects of global warming on energy use for space heating and cooling in the United States. Energy J 16:77-96

Rutberg MJ, Delgado A, Herzog HJ, Ghoniem AF (2011) A system-level generic model of water use at power plants and its application to regional water use estimation. 513-523. doi: https://oi.org/10.1115/IMECE2011-63786

Sailor DJ (2001) Relating residential and commercial sector electricity loads to climate - evaluating state level sensitivities and vulnerabilities. Energy 26:645-657. https://doi.org/10.1016/S0360-5442(01)00023-8

Sailor DJ, Muñoz JR (1997) Sensitivity of electricity and natural gas consumption to climate in the U.S.A.methodology and results for eight states. Energy 22:987-998. https://doi.org/10.1016/S0360-5442(97)00034-0

Sailor DJ, Pavlova AA (2003) Air conditioning market saturation and long-term response of residential cooling energy demand to climate change. Energy 28:941-951. https://doi.org/10.1016/S0360-5442(03)00033-1

Sullivan P, Colman J, Kalendra E (2015) Predicting the response of electricity load to climate change. National Renewable Energy Laboratory (NREL), Golden, CO (United States)

Taylor KE, Stouffer RJ, Meehl GA (2011) An overview of CMIP5 and the experiment design. Bull Am Meteorol Soc 93:485-498. https://doi.org/10.1175/BAMS-D-11-00094.1

Thomson AM, Calvin KV, Smith SJ et al (2011) RCP4.5: a pathway for stabilization of radiative forcing by 2100. Clim Chang 109:77. https://doi.org/10.1007/s10584-011-0151-4

Tidwell VC, Zemlick K, Klise G (2013) Nationwide water availability data for energy-water modeling. Sandia National Laboratories

Tidwell VC, Moreland BD, Zemlick KM et al (2014) Mapping water availability, projected use and cost in the western United States. Environ Res Lett 9:064009. https://doi.org/10.1088/1748-9326/9/6/064009

van Vliet MTH, Yearsley JR, Ludwig F et al (2012) Vulnerability of US and European electricity supply to climate change. Nat Clim Chang 2:676-681. https://doi.org/10.1038/nclimate1546

van Vliet MTH, Wiberg D, Leduc S, Riahi K (2016) Power-generation system vulnerability and adaptation to changes in climate and water resources. Nat Clim Chang 6:375-380. https://doi.org/10.1038/nclimate2903

Ward DM (2013) The effect of weather on grid systems and the reliability of electricity supply. Clim Chang 121: 103-113. https://doi.org/10.1007/s10584-013-0916-z

Wenz L, Levermann A, Auffhammer M (2017) North-south polarization of European electricity consumption under future warming. Proc Natl Acad Sci 114:E7910-E7918. https://doi.org/10.1073/pnas.1704339114

Zhou Y, Eom J, Clarke L (2013) The effect of global climate change, population distribution, and climate mitigation on building energy use in the U.S. and China. Clim Chang 119:979-992. https://doi.org/10.1007 /s10584-013-0772-x

Zhou Y, Clarke L, Eom J et al (2014) Modeling the effect of climate change on U.S. state-level buildings energy demands in an integrated assessment framework. Appl Energy 113:1077-1088. https://doi.org/10.1016/j. apenergy.2013.08.034

Publisher's note Springer Nature remains neutral with regard to jurisdictional claims in published maps and institutional affiliations.

\section{Affiliations}

\section{Daniel C. Steinberg ${ }^{1} \cdot$ Bryan K. Mignone ${ }^{2} \cdot$ Jordan Macknick $^{1} \cdot$ Yinong Sun $^{1} \cdot$ Kelly $^{\prime}$ Eurek $^{1} \cdot$ Andrew Badger $^{3} \cdot$ Ben Livneh $^{3,4} \cdot$ Kristen Averyt $^{5}$}

1 National Renewable Energy Laboratory, Golden, CO 80401, USA

2 ExxonMobil Research and Engineering Company, Annandale, NJ 08801, USA

3 Cooperative Institute for Research in Environmental Sciences, University of Colorado Boulder, Boulder, CO 80309, USA

4 Department of Civil, Environmental, and Architectural Engineering, University of Colorado Boulder, Boulder, CO 80309, USA

5 Desert Research Institute, Las Vegas, NV 89119, USA 